\title{
$\beta$-Catenin-A Supporting Role in the Skeleton
}

\author{
Natasha Case ${ }^{1}$ and Janet Rubin ${ }^{1,2,{ }^{*}}$ \\ ${ }^{1}$ Department of Medicine, University of North Carolina, Chapel Hill, North Carolina 27599 \\ ${ }^{2}$ Department of Pharmacology, University of North Carolina, Chapel Hill, North Carolina 27599
}

\section{Abstract}

In the last 5 years a role for $\beta$-catenin in the skeleton has been cemented. Beginning with mutations in the Lrp5 receptor that control $\beta$-catenin canonical downstream signals, and progressing to transgenic models with bone-specific alteration of $\beta$-catenin, research has shown that $\beta$-catenin is required for normal bone development. A cell critical to bone in which $\beta$-catenin activity determines function is the marrow-derived mesenchymal stem cell (MSC), where sustained $\beta$-catenin prevents its distribution into adipogenic lineage. $\beta$-catenin actions are less well understood in mature osteoblasts: while $\beta$-catenin contributes to control of osteoclastic bone resorption via alteration of the osteoprotegerin/RANKL ratio, a specific regulatory role during osteoblast bone synthesis has not yet been determined. The proven ability of mechanical factors to prevent $\beta$-catenin degradation and induce nuclear translocation through Lrp-independent mechanisms suggests processes by which exercise might modulate bone mass via control of lineage allocation, in particular, by preventing precursor distribution into the adipocyte pool. Effects resulting from mechanical activation of $\beta$-catenin in mature osteoblasts and osteocytes likely modulate bone resorption, but whether $\beta$-catenin is involved in osteoblast synthetic function remains to be proven for both mechanical and soluble mediators. As $\beta$-catenin appears to support the downstream effects of multiple osteogenic factors, studies clarifying when and where $\beta$ catenin effects occur will be relevant for translational approaches aimed at preventing bone loss and terminal adipogenic conversion.

\section{Keywords}

MECHANICAL; ADIPOCYTE; OSTEOBLAST; STRAIN; GSK3 $\beta$

To activate canonical Wnt signaling, a daunting list of Wnt ligands, their extracellular binding proteins and receptors, and a host of associated intracellular proteins are recruited, sorted, ordered, and assembled for the purpose of regulating crucial events in the life of a cell. Emerging out of this extravaganza of molecules is a single non-redundant and central molecule, $\beta$-catenin [Grigoryan et al., 2008]. Once released from alternative fatessequestration, complex binding, or degradation, $\beta$-catenin translocates to the nucleus, binds to Tcf/Lef transcription factors, and triggers cell processes. While $\beta$-catenin signals are evolutionarily ancient [Logan and Nusse, 2004] and have been scientifically scrutinized since the early 1980s, the importance of $\beta$-catenin for bone biology has only recently come to light. Two clinical observations showed that alterations in Wnt downstream signaling profoundly impact skeletal morphology. First, a mutation in the Wnt co-receptor Lrp5 leading to a constitutively "on" signal results in high bone mass, as demonstrated in several

(C) 2010 Wiley-Liss, Inc.

*Correspondence to: Janet Rubin, MD, Department of Medicine, University of North Carolina, 5032 Burnett-Womack, CB \#7170, Chapel Hill, NC 27599. jrubin@ med.unc.edu. 
human kindreds [Boyden et al., 2002; Little et al., 2002]. The yin to this yang emerged when a dominant negative mutation of the same Wnt receptor was found to be associated with low bone mass [Gong et al., 2001], a finding that delighted bone scientists. While many reports mounted proving that modifiers of Wnt production and binding were associated with bone morphology [Williams and Insogna, 2009], the mainstay of Wnt signaling in bone has largely been through a signaling bottleneck where, emerging on the other side, is the singular molecule, $\beta$-catenin.

One might be tempted to consider that Wnt signaling in bone extends beyond $\beta$-catenin. Investigation of other mutations causing altered bone mass resulted in discovery of sclerostin [Brunkow et al., 2001], dickkopf-1 [Tian et al., 2003], and sFRP1 [Bodine et al., 2004], all which interfere with Wnt binding. The LRP5/6 receptor itself has been offered as a key mechanical regulator of bone mass [Sawakami et al., 2006]. Non-canonical signaling through Wnt5a, which represses PPAR $\gamma$ transactivation, was suggested to be an equally important regulator [Takada et al., 2007]. Howsoever, the majority of effects due to these molecules can be chalked up to their ability to regulate the activation of $\beta$-catenin in specific locations and temporal sequences. In sum, any modification that amplifies or diminishes $\beta$ catenin signaling will result in changes in bone mass.

\section{MODIFICATION OF $\beta$-catenin ACTION LEADS TO ALTERATIONS IN BONE FORMATION AND RESORPTION}

Pinpointing the role of $\beta$-catenin in bone biology has been served by the ability to alter $\beta$ catenin in a tissue-specific manner. Global knockout of $\beta$-catenin in mice leads to embryonic lethality [Haegel et al., 1995; Grigoryan et al., 2008]. As such, many of the coregulators of $\beta$-catenin activation have been mutated, leading to the idea that modulationup or down —of $\beta$-catenin activity would lead to proportionately affected bone similar to modulation of the activity of the Wnt co-receptor Lrp5/6. An example of this is the transgenic deletion of Axin2, a molecule which, as part of a multiprotein complex, represses $\beta$-catenin signaling by targeting catenin for proteosomal degradation; after 6 months a phenotype resulting from increased osteoblast proliferation and differentiation as well as decreased osteoclast formation (presumably due to $\beta$-catenin-induced increases in osteoprotegerin) was found [Yan et al., 2009]. Nuclear $\beta$-catenin protein levels were increased, and an in vitro deletion of the $\beta$-catenin gene in this background reversed the osteoblast function in culture [Yan et al., 2009].

Loss of function $\beta$-catenin mutations were first introduced into osteoprogenitor cells through mating either Prx1 or Dermo1-Cre to floxed $\beta$-catenin transgenics. In 2005 three articles proved $\beta$-catenin's fundamental role in osteoblast differentiation. After clearly demonstrating nuclear $\beta$-catenin upregulation during skeletal development in the mouse, Day et al. [2005] conditionally ablated $\beta$-catenin in early mesenchymal condensations with a Dermo1-Cre strategy and showed loss of both osteoblastic and chondrocytic differentiation. When they utilized a Col2a1-Cre strategy to ablate $\beta$-catenin instead, such that $\beta$-catenin knockout occurred later during osteoprogenitor differentiation, expansion of the hypertrophic chondrocyte region was seen. Similarly, Hill et al. explored $\beta$-catenin deletion in limb and head mesenchyme using Prx1-driven Cre-recombinase and were able to show arrest of osteoblast differentiation in membranous and endochondral bones. These scientists also noted that periosteal cells differentiated into chondrocytes in the absence of $\beta$-catenin [Hill et al., 2005]. Importantly their data suggested that while early osteoblast differentiation may occur in the absence of $\beta$-catenin, it ceases at the commitment step where osterix activation becomes necessary for further osteoblast maturation. The third contemporaneous article further explicated a role for $\beta$-catenin during osteoprogenitor differentiation: a Dermo1-cre conditional $\beta$-catenin knockout studied by Hu et al. [2005] affirmed that $\beta$ - 
catenin was indispensible to the conversion from an early osteoblast cell expressing low levels of alkaline phosphatase and collagen to a mature osteoblast with high alkaline phosphatase and collagen, which goes on to express bone sialoprotein and osteocalcin. These studies thus confirm that the presence of activated $\beta$-catenin is necessary for complete osteoprogenitor differentiation.

Interestingly, a recent study demonstrated that proper regulation of $\beta$-catenin signaling is critical for mesenchymal lineage allocation in the developing mouse. Knockout of the APC protein that binds and sequesters $\beta$-catenin leads to abnormal skeletal development: use of the Col2a1 promoter allowed Cre-mediated recombination and deletion of APC in osteoblast precursors not yet committed to either the osteoblastic or chondrogenic lineage. This leads to massive $\beta$-catenin accumulation in the developing endochondral skeleton and interrupts normal commitment of mesenchymal precursors into both chondrocytic and osteoblastic lineages [Miclea et al., 2009]. These authors conclude that $\beta$-catenin dosing is critical to osteoprogenitor entry, specifying that $\beta$-catenin availability must be restricted at some point for proper osteoblasts to develop, and must be nearly absent for Runx 2 expressing cells to enter the chondrocytic lineage. That both dosing and timing of $\beta$-catenin availability is critical for osteoprogenitor development suggests that other micro-environmental factors interact through focusing $\beta$-catenin signaling.

Phenotypic and functional effects of $\beta$-catenin after the osteoblast phenotype has been established are more controversial. Mice lacking $\beta$-catenin expression in osteoblasts, generated using an osteocalcin-directed $\mathrm{Cre}$, had a severe osteopenic phenotype, complicated by significant increases in osteoclasts [Holmen et al., 2005]. Interestingly, this osteoblast $\beta$-catenin inactivation caused a hyperresorptive mouse phenotype that appeared more severe than those seen in human dominant negative mutations of LRP5, supporting the idea that $\beta$-catenin shuffles and integrates the transmission of information arriving via Wntindependent avenues, as we shall discuss further below. The large accumulation of osteoclasts in this osteocalcin-directed $\beta$-catenin knockout model indicated that effects extended beyond osteoblasts.

Similarly, Glass et al. [2005] found alterations in osteoclasts after altering $\beta$-catenin in mature osteoblasts. Using gain-of-function (a $\beta$-catenin resistant to ubiquitination and degradation) or loss-of-function $\beta$-catenin mutations in osteoblasts, that is, using a collagen $a_{1}(\mathrm{I})$ promoter either driving the mutant catenin or a Cre-recombinase, this group showed that while $\beta$-catenin overexpression caused lethality due to osteopetrosis, osteoblast numbers remained at essentially normal levels [Glass et al., 2005]. While the failure of these investigators to find increased osteoblast numbers during $\beta$-catenin overexpression was certainly due to the later onset of the $\beta$-catenin signal as driven by temporal onset of the collagen $\alpha_{1}(I)$ promoter, osteoclast numbers were decreased as a result of increased osteoprotegerin secretion. The latter was presumably due to $\beta$-catenin induction of osteoprotegerin in mature osteoblasts. Alternatively, in animals where osteoblasts expressed the loss-of-function $\beta$-catenin mutation, osteoclasts were abundant resulting in a high bone turnover state with subsequent osteopenia [Glass et al., 2005]. As such, these investigators reconsidered the role of $\beta$-catenin, arriving at their controversial conclusion that $\beta$-catenin's role as it related to bone was largely to modify gut secretion of serotonin, which then would secondarily control osteoprogenitor maturation [Yadav et al., 2008]. This opinion not only blurred the uncontestable role of $\beta$-catenin in the early allocation of mesenchymal stem cells (MSCs) but also appeared to discount their own data showing that the gain-of-function mutants had increased collagen production. This latter effect on osteoblast function was replayed in the global Axin2 knockout which expresses not only increased osteoprotegerin but also collagen 1 by mature osteoblasts [Yan et al., 2009]. Similarly, deletion of the sclerostin gene led to upregulation of canonical signaling, again with an increase in collagen 
1 and osteocalcin expression [Lin et al., 2009]. At this time, activation of $\beta$-catenin in osteoblasts requires further investigation.

\section{MULTIPLE REGULATORS IMPACT $\beta$-catenin ACTIVATION}

$\beta$-catenin can be found in two primary cellular locations which determine its dual roles in cell function. A pool of $\beta$-catenin associated with the plasma membrane is bound to Ecadherin and $\alpha$-catenin in adherens junctions. $\beta$-catenin at this location is an essential component of junction physiology, and accumulates here when incoming signals fail to activate its nuclear translocation [Cadigan and Peifer, 2009]. The participation of $\beta$-catenin in cell- cell adhesion through these intracellular networks contributes to vertebrate development through regulation of multiple processes [Stepniak et al., 2009], effects only beginning to be appreciated in skeletal development. Much more attention has been paid to the soluble pool of $\beta$-catenin found in the cytoplasm, which, upon appropriate stimulation, is translocated to the nucleus to interact with Tcf/Lef transcription factors. The availability of $\beta$-catenin in the cytoplasm is regulated by a destruction complex consisting of axin, GSK3 $\beta$, and APC. Constitutive phosphorylation of $\beta$-catenin by cyclin-dependent kinase at serine-45 followed by phosphorylation of the $\mathrm{N}$-terminus by GSK3 $\beta$ targets $\beta$-catenin for degradation by the ubiquitin/proteosome pathway, limiting levels of cytoplasmic $\beta$-catenin under resting conditions. As such, stabilization of $\beta$-catenin in the cytosol, enabling nuclear translocation, depends upon inhibition of $\beta$-catenin phosphorylation.

In canonical Wnt signaling, binding of Wnt ligand to its transmembrane receptors frizzled and LRP5/6 leads to disruption of the $\beta$-catenin destruction complex, which appears to be mediated through dissociation of axin-GSK3 $\beta$ interactions as well as direct inhibition of GSK3 $\beta$ [MacDonald et al., 2009]. While activation of $\beta$-catenin has traditionally been associated with signaling through the canonical Wnt pathway, it is now recognized that multiple signaling pathways can activate $\beta$-catenin. For example, the putative anti-aging drug resveratrol has been used in vitro to show that $\beta$-catenin increases in the nucleus through an Lrp5/6- independent fashion, possibly also due to inhibition of GSK3 $\beta$, promoting osteoblastic differentiation [Zhou et al., 2009].

As the primary mediator of $\beta$-catenin phosphorylation, GSK3 $\beta$ activity is critical for regulating cytosolic $\beta$-catenin levels. Importantly, inhibition of GSK3 $\beta$ with lithium, or small molecule inhibitors, leads to preservation of $\beta$-catenin and magnifies activation-this results in an increase in osteoprogenitor cells and their activity [Sawakami et al., 2006; Sen et al., 2009; Yan et al., 2009]. One pathway for inactivation of GSK3 $\beta$ is by phosphorylation at serine-9, originally described for insulin signaling through Akt/protein kinase B. Studies in non-skeletal tissues have described $\beta$-catenin activation mediated by phosphorylation of GSK3 $\beta$ by Akt downstream of signaling through heterotrimeric $G$ protein-coupled receptors [Haq et al., 2003; Castellone et al., 2005], a possibility which will certainly have implications for the skeleton.

An environmental constraint critical to normal bone modeling and remodeling is generated through mechanical loading. Mechanical stimulation also impacts processes resulting in $\beta$ catenin activation in bone cells at all stages of maturation, from the undifferentiated MSC [Sen et al., 2008] to differentiating osteoblasts [Case et al., 2008] to early osteocytes [Xia et al., 2010]. $\beta$-catenin translocates into the nucleus after loading of osteoblasts in response to either substrate deformation or fluid flow [Norvell et al., 2004; Armstrong et al., 2007], where it can activate a $\beta$-catenin responsive promoter sequence [Hens et al., 2005]. This is clearly visible in the appearance of activated (dephospho-form) $\beta$-catenin in osteoblast like cells that have been subject to strain, as well as its translocation into the nucleus, as shown in Figure 1. Accordingly, mechanical loading upregulates $\beta$-catenin target genes in vivo 
[Robinson et al., 2006] and in vitro [Lau et al., 2006]. Mechanical regulation of these target genes might contribute to loading-induced bone formation in several ways. Cyclin D1, a well-recognized target of $\beta$-catenin, induces cell proliferation, and it has been shown that inhibition of Wnt signals with endostatin are able to prevent fluid shear-induced proliferation of osteoblasts [Lau et al., 2006]. Mechanical induction of WISP1, a gene associated with osteogenesis [French et al., 2004], and that we have shown to be rapidly upregulated by $\beta$-catenin activation [Case et al., 2008], may as well support enhanced osteoblast function.

The mechanical effect on $\beta$-catenin target genes is enhanced in the Lrp5 ("on") transgenic mouse with high bone mass, where Wnt signaling is constitutively activated [Robinson et al., 2006]. Conversely, mice with a loss-of-function mutation in LRP5 respond poorly to local bone loading [Sawakami et al., 2006], which led these authors to suggest that Wnt binding was necessary for mechanical effects, in particular those due to $\beta$-catenin. Our data suggests that this is not true: in both osteoblasts and MSCs, mechanical activation of $\beta$ catenin was unaffected by the presence of DKK-1, an antagonist that prevents Wnt ligation of Lrp receptors [Case et al., 2008; Sen et al., 2009]. The ability of mechanical strain to induce $\beta$-catenin activation in the presence of blocked Lrp function has been confirmed [Sunters et al., 2010]. Perhaps a better interpretation of the Sawakami data is that in situations where $\beta$-catenin availability is modulated, incoming signals which activate or otherwise impact $\beta$-catenin signaling will be proportionately affected. As such, in states where more $\beta$-catenin is actionable, factors-mechanical or chemical-impacting the proximal side of the bottleneck will cause greater downstream effects.

Tracing the mechanical steps from $\beta$-catenin activation proximally to where potential mechanoreceptors are subject to membrane deformations, revealed that strain-induced phosphorylation of GSK3 $\beta$ on a site that prevents its binding to $\beta$-catenin, thus reducing catenin ubiquitination and proteolysis [Armstrong et al., 2007; Case et al., 2008]. Even more rapidly, strain also induced activation of Akt, which likely phosphorylates and inhibits GSK3 $\beta$ [Case et al., 2008; Sunters et al., 2010, \#1711]. Effectors of Akt, or alternate means by which GSK3 $\beta$ is inhibited by phosphorylation, remain to be identified. PI3K is a possible candidate as it is known to be activated by mechanical force, and PI3K downstream of IGF-1 receptor signaling was found to be necessary for late $(3 \mathrm{~h})$ strain-induced Akt activation in osteoblast-like cells [Sunters et al., 2010]. Our own data suggests that PI3K is not involved in immediate Akt activation and GSK3 $\beta$ inhibition [Case et al., 2008], opening other possibilities such as integrin-linked kinase (ILK) as intermediaries in mechanical induction of $\beta$-catenin (see Fig. 2).

$\beta$-catenin might also be regulated by mechanical or other signals through a change in membrane sequestration. Membrane proteins, such as cadherins in the adherens junctions, may be able to regulate the availability of $\beta$-catenin, thereby contributing to regulation of cellular events [Mbalaviele et al., 2006]. An association between $\beta$-catenin and $\mathrm{N}$-cadherin was decreased in osteoblasts in response to fluid flow [Norvell et al., 2004]. Interestingly, caveolin-1, a structural membrane protein involved in lipid raft compartmentalization, can also sequester $\beta$-catenin, such that overexpression of caveolin-1 damps catenin signaling [Galbiati et al., 2000], and may contribute to the increased bone mass in the caveolin-1 knockout animal [Rubin et al., 2007].

\section{A CENTRAL ROLE FOR $\beta$-catenin IN MSC LINEAGE ALLOCATION}

The list of cells involved in determination of skeletal morphology has grown beyond the osteoblast, osteocyte, and osteoclast. Perhaps the most important with regard to $\beta$-catenin signaling is the bone marrow MSC. The output of this pool of MSCs reflects a reciprocal 
relationship between the numbers of osteoblasts and adipocytes [Akune et al., 2004]. On the level of the whole animal, a lineage reciprocity between fat and bone is apparent in the case where the Lrp5 receptor is constitutively activated, where increased trabecular bone is accompanied by decreased fat in bone marrow [Qiu et al., 2007]. Further, Wnt repression of adipogenesis in MSCs requires stabilization of $\beta$-catenin, which then promotes subsequent entry into the osteoprogenitor lineage [Kennell and MacDougald, 2005]. Our laboratory has shown that small molecule inhibitors of GSK3 $\beta$ prevent adipogenesis in MSCs, coincident with a failure of adipogenic conditions to cause reduction in intracellular active and total $\beta$ catenin levels [Sen et al., 2008]. Importantly, GSK3 $\beta$ inhibition did not prevent adipogenesis when $\beta$-catenin protein was knocked down with siRNAs [Sen et al., 2009] (see Fig. 3), a fact that underlines the critical role of $\beta$-catenin in the proscription of adipocyte entry. This is further underlined with the fact that the Wnt effect to restrain further differentiation of preadipocytes by limiting expression of PPAR $\gamma$ can be overcome by measures that decrease $\beta$-catenin signaling [Ross et al., 2000]. As such, it is clear that a branch point exists where the disposition of MSCs toward the adipocyte lineage critically hinges on the level of actionable intracellular $\beta$-catenin.

Given that mechanical loading activates $\beta$-catenin signaling in osteoblasts, we considered that $\beta$-catenin might also be subject to mechanical regulation in MSCs. Our laboratory recently demonstrated that mechanical signals participate in directly regulating lineage selection of mesenchymal precursors, mediated in part through mechanical effects on $\beta$ catenin. Specifically, daily mechanical input effectively counteracted an adipogenic stimulus, disrupting differentiation of C3H10T1/2 mesenchymal progenitor cells [Sen et al., 2008]. In cultures receiving daily strain, accumulation of intracellular lipid was significantly reduced, as was expression of PPAR $\gamma$ and adiponectin. Mechanical signals completely prevented the progressive decrease in $\beta$-catenin that was found to accompany adipogenic transformation in MSCs. Importantly, small interfering RNA targeting $\beta$-catenin blocked the ability of strain to inhibit adipogenesis of both $\mathrm{C} 3 \mathrm{H} 10 \mathrm{~T} 1 / 2$ and marrow-derived MSCs [Sen et al., 2009]. Mechanical preservation of $\beta$-catenin in MSCs was shown to be downstream of mechanical inactivation of GSK3 $\beta$ and this effect was independent of signaling through Wnt receptors, consistent with the signaling pathway described in osteoblasts. Beyond the branch point between adipogenesis and osteogenesis, $\beta$-catenin signaling appears to be secondary to a host of osteogenic signals including BMPs, hedgehog, and activation of SMAD signaling pathways. Actions of $\beta$-catenin may be influenced by BMP signaling, as there is crosstalk between the two pathways [Itasaki and Hoppler, 2010]. Furthermore, we were able to show that MSCs subject to a mechanical regimen while under adipogenic constraints were able to respond rapidly and completely to BMP2 due to the high levels of $\beta$-catenin induced by the daily strain [Sen et al., 2008].

Recently, Wnt1 dosing experiments in human MSCs allowed investigators to argue that Wnts, presumably via $\beta$-catenin, has variable effects on different pools of MSCs, such that early canonical signaling prevents adipogenesis and promotes expansion of the osteoprogenitor clone, which then must experience decreased TCF4 signaling, or at the least, other signals, to achieve the mature osteoblastic phenotype [Liu et al., 2009]. Whether $\beta$ catenin exercises a dominant influence beyond the branch point between adipogenesis and osteogenesis is not firmly established. As discussed earlier, commitment within the osteoblast lineage does appear to require $\beta$-catenin activity: the dermo1-Cre conditional $\beta$ catenin knockout showed that E18.5 embryos had a cartilaginous skeleton but no bone or functioning osteoblasts [Hu et al., 2005]. Similarly, an Osterix-cre mouse where conditional ablation of the $\beta$-catenin gene was restricted to late osteoprogenitors, the normal size cartilaginous skeleton was not mineralized [Rodda and McMahon, 2006]. Importantly, the obverse, that is stabilization of $\beta$-catenin signaling in osterix expressing osteoprogenitors, 
resulted in premature mineralization and increased proliferation of preosteoblasts [Rodda and McMahon, 2006], supporting a role for $\beta$-catenin in controlling late osteoblast function.

In sum, although the activation of $\beta$-catenin in differentiating osteoprogenitors represents an incompletely understood integration of multiple signals from the micro-environment, the contribution of $\beta$-catenin towards delineation of lineage within the MSC pool is incontrovertible. $\beta$-catenin prevents adipogenic differentiation, supports early osteochondroprogenitor entry, and its absence after this point promotes entry into the chondrocytic pathway.

\section{$\beta$-catenin: MAJOR OR SUPPORTING PLAYER IN MECHANICAL SIGNAL TRANSDUCTION?}

Mechanical information is critical to functional bone morphology. Adaptation to mechanical loading is a tissue-level response that involves temporal and spatial coordination of bone cells, and thus in vivo models of bone adaptation provide primary insights into the cellular events leading to new bone formation. Experimental data suggests that mechanical signals can activate the resident quiescent osteoblast population: a role for $\beta$-catenin seems logical here, and indeed Lrp5 resistant animals have a poor mechanical response to loading [Sawakami et al., 2006]. In the case of the osteocyte, which serves as a mechanical sensor controlling bone resorption in response to unloading [Tatsumi et al., 2007], it is likely that $\beta$-catenin will be shown to be an important signal node in osteocyte induction of osteoclastogenesis. Bone formation upon re-loading, however, proceeds in the absence of functional osteocytes [Tatsumi et al., 2007], and no other data yet exists to show that osteocytes rely on mechanically induced $\beta$-catenin signaling.

The contribution of $\beta$-catenin towards delineation of lineage within the MSC pool is, however, well established. As such, in considering the role of $\beta$-catenin as an effector of mechanical signaling in bone, we can achieve some certitude by focusing our comments on mechanical influences on MSC recruitment and differentiation. Animal studies suggest that MSC lineage allocation within the marrow cavity is subject to mechanical input, with exercise increasing the proportion of marrow precursors assigned to the osteogenic lineage [David et al., 2007; Menuki et al., 2008]. As adipocyte numbers in the marrow are coordinately reduced by exercise in these studies, this pro-osteogenic effect may be due in part to a blocking of MSCs entering the adipogenic pathway, thus preserving a pool of cells available for alternate lineages. Furthermore, MSC allocation has been shown to be affected in vivo by exogenous vibration, a novel strategy for delivering therapeutic loading signals [Luu et al., 2009]. Indeed, in vitro experimentation has demonstrated that mechanical signals directly inhibit adipocyte differentiation of MSCs [Sen et al., 2008] and that mechanical activation of $\beta$-catenin is critical to this effect [Sen et al., 2009].

Our lab also demonstrated that mechanical strain induced COX2 expression [Sen et al., 2009]. The mechanical response of COX2, interestingly, was unchanged in the presence of $\beta$-catenin knockdown by small interfering RNA, in contrast to mechanical inhibition of adipogenesis. Similarly to its role in preserving $\beta$-catenin, mechanical inactivation of GSK $3 \beta$ was necessary for strain effects on COX2. In this case, mechanical inactivation of GSK $3 \beta$ was found to have a secondary effect to promote nuclear accumulation of NFATc1 through preventing GSK3 $\beta$ 's re-phosphorylation of nuclear NFATc1 with reentry to the cytoplasm [Sen et al., 2009]. Silencing of NFATc1 with siRNA prevented mechanical stimulation of COX2. Importantly, strain effects on NFATc1 and COX2 did not require $\beta$ catenin (see Fig. 3). Since an increase in COX2 is associated with differentiation of osteoblasts [Zhang et al., 2002], mechanical upregulation of COX2 is likely to be only one 
of a host of mechanically susceptible pathways which influence bone formation. As such, the primacy of $\beta$-catenin is not established.

Limited in vitro data exist to suggest a direct role for mechanical loading in promoting osteogenic differentiation of MSCs in the absence of added factors. Mechanical signals that activate $\beta$-catenin, as well as other effector molecules, may provide too weak of a differentiation stimulus by themselves, but may enhance entry into the osteogenic lineage when working in concert with other signals such as BMP-2 [Case et al., 2008; Sen et al., 2008]. Taking this idea a step further, mechanical protection of $\beta$-catenin levels appears to assume a permissive role, allowing proliferation and expansion of early-but not committed -osteoprogenitors, and enabling these cells to resist differentiation factors that promote other lineages, for example, adipogenic or chondrogenic stimuli. As such, when soluble factors promoting late osteoblast development exceed some threshold, the $\beta$-catenin brake on differentiation would be released in favor of osteogenesis (see Fig. 4).

Activation of $\beta$-catenin is certainly a strong signal contributing to osteoclastogenesis via regulation of RANKL expression in osteoblasts, a fact consistent with the mechanical downregulation of RANKL [Rubin et al., 2000]. Restriction of RANKL is likely prima facie to the ability of exercise to inhibit bone resorption. In transgenic animals where a form of $\beta$ catenin expressed in osteoblasts was stabilized by preventing targeting by GSK $3 \beta$, osteopetrosis developed [Glass et al., 2005]. Whether the mechanical inhibition of RANKL absolutely requires $\beta$-catenin is not yet known.

It is understood that activation of $\beta$-catenin is not responsible for transducing all of the various cellular events associated with mechanical stimulation in bone cells; rather multiple parallel signaling pathways with various downstream effector molecules are initiated by membrane deformations to mediate these cellular effects, as reviewed in [Rubin et al., 2006]. Integrin-associated proteins, including focal adhesion kinase (FAK) and ILK, are likely candidates for initiating mechanical signaling cascades in bone cells. Signaling through $G$ proteins and $G$ protein-coupled receptors may contribute to mechanical activation of ERK 1/2 MAP kinase and PI3 kinase, respectively. It is noteworthy that several of these pathways are known to regulate activity of GSK3 $\beta$ in response to chemical factors, suggesting a possible point of convergence in response to mechanical inputs. GSK3 $\beta$ has other effectors besides $\beta$-catenin, as we have shown in the case of NFATc1 above [Sen et al., 2009]. At this point, it is clear that activation of $\beta$-catenin is a major target of mechanical input, at the very least an important node where biophysical factors control MSC cell fate, but its role in other, less well-defined responses to loading, such as the mechanosensory response of osteocytes, remains to be elucidated.

\section{CONCLUSION}

In summary, $\beta$-catenin has an irreplaceable role in bone marrow MSCs, where temporal and dosing effects regulate lineage allocation (reviewed in Fig. 4). There are at least two critical decision points where $\beta$-catenin activity exerts predominant control - at the selection node between adipocyte and osteoprogenitor progression, and later, when a portion of osteoprogenitor cells enter the chondrogenic lineage. At each of these points, the availability or unavailability of $\beta$-catenin determines lineage. In the case of MSCs exposed to a microenvironment which favors development of a fat phenotype, elevated levels of $\beta$-catenin protected from proteosomal degradation prevent adipogenesis. At this stage, an elevated $\beta$ catenin level appears to be permissive signal for progression into the osteoblast phenotype rather than a primary stimulus; it is likely that other factors, in particular those in the BMP and hedgehog signaling pathways, direct the osteoblastic transformation. In terms of chondrogenesis, less is known, but it also appears that $\beta$-catenin again prevents allocation 
into chondrocyte lineage; as such $\beta$-catenin levels must fall, similarly to the loss required for adipogenesis, before chondrogenesis can occur. As such, during MSC development $\beta$ catenin plays a permissive role, preventing final lineage assignment.

An effect of $\beta$-catenin in differentiated bone cells, including osteoblasts and osteocytes, remains inferential-while $\beta$-catenin is available for activation, and has been shown to be regulated by a multitude of factors both physical and chemical, downstream targets other than osteoprotegerin with affects on osteoclast recruitment, are not well understood. This invites further thought and study.

Mechanical stimulation, known to promote bone formation, and certainly to prevent bone resorption, has been proven to regulate $\beta$-catenin levels in MSCs and in differentiated osteoblasts and osteocytes both in vitro and in vivo. Mechanical signals prevent $\beta$-catenin degradation through regulation of GSK3 $\beta$ activity by Wnt independent means. Wnt signaling, as well as effects on $\beta$-catenin via other growth receptors, in response to mechanical input may contribute as well. The capacity of mechanical signals to promote an osteogenic environment through preventing alternate lineage selection suggests many opportunities whereby biophysical factors could be used to regulate the output of the marrow MSC pool.

In closing, the conjunction of $\beta$-catenin as a key regulator of MSC lineage allocation, and the ability of biophysical factors to regulate both $\beta$-catenin and MSC cell fate, calls for research that will define the optimal way to dose both of these factors-exercise and $\beta$ catenin - to promote the health and strength of the skeleton.

\section{Acknowledgments}

Grant sponsor: NIAMS; Grant numbers: AR42360, AR52014.

\section{REFERENCES}

Akune T, Ohba S, Kamekura S, Yamaguchi M, Chung UI, Kubota N, Terauchi Y, Harada Y, Azuma Y, Nakamura K, Kadowaki T, Kawaguchi H. PPARgamma insufficiency enhances osteogenesis through osteoblast formation from bone marrow progenitors. J Clin Invest. 2004; 113:846-855. [PubMed: 15067317]

Armstrong VJ, Muzylak M, Sunters A, Zaman G, Saxon LK, Price JS, Lanyon LE. Wnt/beta-catenin signaling is a component of osteoblastic bone cells' early responses to load-bearing, and requires estrogen receptor alpha. J Biol Chem. 2007; 282:20715-20727. [PubMed: 17491024]

Bodine PV, Zhao W, Kharode YP, Bex FJ, Lambert AJ, Goad MB, Gaur T, Stein GS, Lian JB, Komm BS. The Wnt antagonist secreted frizzled-related protein-1 is a negative regulator of trabecular bone formation in adult mice. Mol Endocrinol. 2004; 18:1222-1237. [PubMed: 14976225]

Boyden LM, Mao J, Belsky J, Mitzner L, Farhi A, Mitnick MA, Wu D, Insogna K, Lifton RP. High bone density due to a mutation in LDL-receptor-related protein 5. N Engl J Med. 2002; 346:15131521. [PubMed: 12015390]

Brunkow ME, Gardner JC, Van Ness J, Paeper BW, Kovacevich BR, Proll S, Skonier JE, Zhao L, Sabo PJ, Fu Y, Alisch RS, Gillett L, Colbert T, Tacconi P, Galas D, Hamersma H, Beighton P, Mulligan J. Bone dysplasia sclerosteosis results from loss of the SOST gene product, a novel cystine knot-containing protein. Am J Hum Genet. 2001; 68:577-589. [PubMed: 11179006]

Cadigan KM, Peifer M. Wnt signaling from development to disease: Insights from model systems. Cold Spring Harbor Perspect Biol. 2009; 1:a002881.

Case N, Ma M, Sen B, Xie Z, Gross TS, Rubin J. Beta-catenin levels influence rapid mechanical responses in osteoblasts. J Biol Chem. 2008; 283:29196-29205. [PubMed: 18723514] 
Castellone MD, Teramoto H, Williams BO, Druey KM, Gutkind JS. Prostaglandin E2 promotes colon cancer cell growth through a Gs-axin-beta-catenin signaling axis. Science. 2005; 310:1504-1510. [PubMed: 16293724]

David V, Martin A, Lafage-Proust MH, Malaval L, Peyroche S, Jones DB, Vico L, Guignandon A. Mechanical loading down-regulates peroxisome proliferator-activated receptor gamma in bone marrow stromal cells and favors osteoblastogenesis at the expense of adipogenesis. Endocrinology. 2007; 148:2553-2562. [PubMed: 17317771]

Day TF, Guo X, Garrett-Beal L, Yang Y. Wnt/beta-catenin signaling in mesenchymal progenitors controls osteoblast and chondrocyte differentiation during vertebrate skeletogenesis. Dev Cell. 2005; 8:739-750. [PubMed: 15866164]

French DM, Kaul RJ, D’Souza AL, Crowley CW, Bao M, Frantz GD, Filvaroff EH, Desnoyers L. WISP-1 is an osteoblastic regulator expressed during skeletal development and fracture repair. Am J Pathol. 2004; 165:855-867. [PubMed: 15331410]

Galbiati F, Volonte D, Brown AM, Weinstein DE, Ben-Ze'ev A, Pestell RG, Lisanti MP. Caveolin-1 expression inhibits Wnt/beta-catenin/Lef-1 signaling by recruiting beta-catenin to caveolae membrane domains. J Biol Chem. 2000; 275:23368-23377. [PubMed: 10816572]

Glass DA III, Bialek P, Ahn JD, Starbuck M, Patel MS, Clevers H, Taketo MM, Long F, McMahon AP, Lang RA, Karsenty G. Canonical Wnt signaling in differentiated osteoblasts controls osteoclast differentiation. Dev Cell. 2005; 8:751-764. [PubMed: 15866165]

Gong Y, Slee RB, Fukai N, Rawadi G, Roman-Roman S, Reginato AM, Wang H, Cundy T, Glorieux FH, Lev D, Zacharin M, Oexle K, Marcelino J, Suwairi W, Heeger S, Sabatakos G, Apte S, Adkins WN, Allgrove J, Arslan-Kirchner M, Batch JA, Beighton P, Black GC, Boles RG, Boon LM, Borrone C, Brunner HG, Carle GF, Dallapiccola B, De Paepe A, Floege B, Halfhide ML, Hall B, Hennekam RC, Hirose T, Jans A, Juppner H, Kim CA, Keppler-Noreuil K, Kohlschuetter A, LaCombe D, Lambert M, Lemyre E, Letteboer T, Peltonen L, Ramesar RS, Romanengo M, Somer H, Steichen-Gersdorf E, Steinmann B, Sullivan B, Superti-Furga A, Swoboda W, van den Boogaard MJ, Van Hul W, Vikkula M, Votruba M, Zabel B, Garcia T, Baron R, Olsen BR, Warman ML. LDL receptor-related protein 5 (LRP5) affects bone accrual and eye development. Cell. 2001; 107:513-523. [PubMed: 11719191]

Grigoryan T, Wend P, Klaus A, Birchmeier W. Deciphering the function of canonical Wnt signals in development and disease: Conditional loss- and gain-of-function mutations of beta-catenin in mice. Genes Dev. 2008; 22:2308-2341. [PubMed: 18765787]

Haegel H, Larue L, Ohsugi M, Fedorov L, Herrenknecht K, Kemler R. Lack of beta-catenin affects mouse development at gastrulation. Development. 1995; 121:3529-3537. [PubMed: 8582267]

Haq S, Michael A, Andreucci M, Bhattacharya K, Dotto P, Walters B, Woodgett J, Kilter H, Force T. Stabilization of beta-catenin by a Wnt-independent mechanism regulates cardiomyocyte growth. Proc Natl Acad Sci USA. 2003; 100:4610-4615. [PubMed: 12668767]

Hens JR, Wilson KM, Dann P, Chen X, Horowitz MC, Wysolmerski JJ. TOPGAL mice show that the canonical Wnt signaling pathway is active during bone development and growth and is activated by mechanical loading in vitro. J Bone Miner Res. 2005; 20:1103-1113. [PubMed: 15940363]

Hill TP, Spater D, Taketo MM, Birchmeier W, Hartmann C. Canonical Wnt/beta-catenin signaling prevents osteoblasts from differentiating into chondrocytes. Dev Cell. 2005; 8:727-738. [PubMed: 15866163]

Holmen SL, Zylstra CR, Mukherjee A, Sigler RE, Faugere MC, Bouxsein ML, Deng L, Clemens TL, Williams BO. Essential role of beta-catenin in postnatal bone acquisition. J Biol Chem. 2005; 280:21162-21168. [PubMed: 15802266]

Hu H, Hilton MJ, Tu X, Yu K, Ornitz DM, Long F. Sequential roles of Hedgehog and Wnt signaling in osteoblast development. Development. 2005; 132:49-60. [PubMed: 15576404]

Itasaki N, Hoppler S. Crosstalk between Wnt and bone morphogenic protein signaling: A turbulent relationship. Dev Dyn. 2010; 239:16-33. [PubMed: 19544585]

Kennell JA, MacDougald OA. Wnt signaling inhibits adipogenesis through beta-catenin-dependent and -independent mechanisms. J Biol Chem. 2005; 280:24004-24010. [PubMed: 15849360]

Lau KH, Kapur S, Kesavan C, Baylink DJ. Up-regulation of the Wnt, estrogen receptor, insulin-like growth factor-I, and bone morphogenetic protein pathways in C57BL/6J osteoblasts as opposed to 
$\mathrm{C} 3 \mathrm{H} / \mathrm{HeJ}$ osteoblasts in part contributes to the differential anabolic response to fluid shear. J Biol Chem. 2006; 281:9576-9588. [PubMed: 16461770]

Lin C, Jiang X, Dai Z, Guo X, Weng T, Wang J, Li Y, Feng G, Gao X, He L. Sclerostin mediates bone response to mechanical unloading through antagonizing $\mathrm{Wnt} /$ beta-catenin signaling. J Bone Miner Res. 2009; 24:1651-1661. [PubMed: 19419300]

Little RD, Carulli JP, Del Mastro RG, Dupuis J, Osborne M, Folz C, Manning SP, Swain PM, Zhao SC, Eustace B, Lappe MM, Spitzer L, Zweier S, Braunschweiger K, Benchekroun Y, Hu X, Adair R, Chee L, FitzGerald MG, Tulig C, Caruso A, Tzellas N, Bawa A, Franklin B, McGuire S, Nogues X, Gong G, Allen KM, Anisowicz A, Morales AJ, Lomedico PT, Recker SM, Van Eerdewegh P, Recker RR, Johnson ML. A mutation in the LDL receptor-related protein 5 gene results in the autosomal dominant high-bone-mass trait. Am J Hum Genet. 2002; 70:11-19. [PubMed: 11741193]

Liu G, Vijayakumar S, Grumolato L, Arroyave R, Qiao H, Akiri G, Aaronson SA. Canonical Wnts function as potent regulators of osteogenesis by human mesenchymal stem cells. J Cell Biol. 2009; 185:67-75. [PubMed: 19349579]

Logan CY, Nusse R. The Wnt signaling pathway in development and disease. Annu Rev Cell Dev Biol. 2004; 20:781-810. [PubMed: 15473860]

Luu YK, Capilla E, Rosen CJ, Gilsanz V, Pessin JE, Judex S, Rubin CT. Mechanical stimulation of mesenchymal stem cell proliferation and differentiation promotes osteogenesis while preventing dietary-induced obesity. J Bone Miner Res. 2009; 24:50-61. [PubMed: 18715135]

MacDonald BT, Tamai K, He X. Wnt/beta-catenin signaling: Components, mechanisms, and diseases. Dev Cell. 2009; 17:9-26. [PubMed: 19619488]

Mbalaviele G, Shin CS, Civitelli R. Cell-cell adhesion and signaling through cadherins: Connecting bone cells in their microenvironment. J Bone Miner Res. 2006; 21:1821-1827. [PubMed: 17002562]

Menuki K, Mori T, Sakai A, Sakuma M, Okimoto N, Shimizu Y, Kunugita N, Nakamura T. Climbing exercise enhances osteoblast differentiation and inhibits adipogenic differentiation with high expression of PTH/PTHrP receptor in bone marrow cells. Bone. 2008; 43:613-620. [PubMed: 18567552]

Miclea RL, Karperien M, Bosch CA, van der Horst G, van der Valk MA, Kobayashi T, Kronenberg HM, Rawadi G, Akcakaya P, Lowik CW, Fodde R, Wit JM, Robanus-Maandag EC. Adenomatous polyposis coli-mediated control of beta-catenin is essential for both chondrogenic and osteogenic differentiation of skeletal precursors. BMC Dev Biol. 2009; 9:26. [PubMed: 19356224]

Norvell SM, Alvarez M, Bidwell JP, Pavalko FM. Fluid shear stress induces beta-catenin signaling in osteoblasts. Calcif Tissue Int. 2004; 75:396-404. [PubMed: 15592796]

Qiu W, Andersen TE, Bollerslev J, Mandrup S, Abdallah BM, Kassem M. Patients with high bone mass phenotype exhibit enhanced osteoblast differentiation and inhibition of adipogenesis of human mesenchymal stem cells. J Bone Miner Res. 2007; 22:1720-1731. [PubMed: 17680723]

Robinson JA, Chatterjee-Kishore M, Yaworsky PJ, Cullen DM, Zhao W, Li C, Kharode Y, Sauter L, Babij P, Brown EL, Hill AA, Akhter MP, Johnson ML, Recker RR, Komm BS, Bex FJ. WNT/ beta-catenin signaling is a normal physiological response to mechanical loading in bone. $\mathrm{J}$ Biol Chem. 2006; 281:31720-31728. [PubMed: 16908522]

Rodda SJ, McMahon AP. Distinct roles for Hedgehog and canonical Wnt signaling in specification, differentiation and maintenance of osteoblast progenitors. Development. 2006; 133:3231-3244. [PubMed: 16854976]

Ross SE, Hemati N, Longo KA, Bennett CN, Lucas PC, Erickson RL, MacDougald OA. Inhibition of adipogenesis by Wnt signaling. Science. 2000; 289:950-953. [PubMed: 10937998]

Rubin J, Murphy T, Nanes MS, Fan X. Mechanical strain inhibits expression of osteoclast differentiation factor by murine stromal cells. Am J Physiol Cell Physiol. 2000; 278:C1126C1132. [PubMed: 10837340]

Rubin J, Rubin C, Jacobs CR. Molecular pathways mediating mechanical signaling in bone. Gene. 2006; 367:1-16. [PubMed: 16361069] 
Rubin J, Schwartz Z, Boyan BD, Fan X, Case N, Sen B, Drab M, Smith D, Aleman M, Wong KL, Yao H, Jo H, Gross TS. Caveolin-1 knockout mice have increased bone size and stiffness. J Bone Miner Res. 2007; 22:1408-1418. [PubMed: 17550335]

Sawakami K, Robling AG, Ai M, Pitner ND, Liu D, Warden SJ, Li J, Maye P, Rowe DW, Duncan RL, Warman ML, Turner CH. The Wnt co-receptor LRP5 is essential for skeletal mechanotransduction but not for the anabolic bone response to parathyroid hormone treatment. J Biol Chem. 2006; 281:23698-23711. [PubMed: 16790443]

Sen B, Xie Z, Case N, Ma M, Rubin C, Rubin J. Mechanical strain inhibits adipogenesis in mesenchymal stem cells by stimulating a durable beta-catenin signal. Endocrinology. 2008; 149:6065-6075. [PubMed: 18687779]

Sen B, Styner M, Xie Z, Case N, Rubin CT, Rubin J. Mechanical loading regulates NFATc1 and betacatenin signaling through a GSK3beta control node. J Biol Chem. 2009; 284:34607-34617. [PubMed: 19840939]

Stepniak E, Radice GL, Vasioukhin V. Adhesive and signaling functions of cadherins and catenins in vertebrate development. Cold Spring Harbor Perspect Biol. 2009; 1:a002949.

Sunters A, Armstrong VJ, Zaman G, Kypta RM, Kawano Y, Lanyon LE, Price JS. Mechanotransduction in osteoblastic cells involves strain-regulated, estrogen receptor $\{$ alpha\}-mediated, control of IGF-IR sensitivity to ambient IGF, leading to PI3-K/ AKT dependent, Wnt/LRP5 receptor-independent activation of \{beta\}-catenin signaling. J Biol Chem. 2010; 285:8743-8758. [PubMed: 20042609]

Takada I, Mihara M, Suzawa M, Ohtake F, Kobayashi S, Igarashi M, Youn MY, Takeyama K, Nakamura T, Mezaki Y, Takezawa S, Yogiashi Y, Kitagawa H, Yamada G, Takada S, Minami Y, Shibuya H, Matsumoto K, Kato S. A histone lysine methyltransferase activated by non-canonical Wnt signalling suppresses PPAR-gamma transactivation. Nat Cell Biol. 2007; 9:1273-1285. [PubMed: 17952062]

Tatsumi S, Ishii K, Amizuka N, Li M, Kobayashi T, Kohno K, Ito M, Takeshita S, Ikeda K. Targeted ablation of osteocytes induces osteoporosis with defective mechanotransduction. Cell Metab. 2007; 5:464-475. [PubMed: 17550781]

Tian E, Zhan F, Walker R, Rasmussen E, Ma Y, Barlogie B, Shaughnessy JD Jr. The role of the Wntsignaling antagonist DKK1 in the development of osteolytic lesions in multiple myeloma. N Engl J Med. 2003; 349:2483-2494. [PubMed: 14695408]

Williams BO, Insogna KL. Where Wnts went: The exploding field of Lrp5 and Lrp6 signaling in bone. J Bone Miner Res. 2009; 24:171-178. [PubMed: 19072724]

Xia X, Batra N, Shi Q, Bonewald LF, Sprague E, Jiang JX. Prostaglandin promotion of osteocyte gap junction function through transcriptional regulation of connexin 43 by glycogen synthase kinase 3 / beta-catenin signaling. Mol Cell Biol. 2010; 30:206-219. [PubMed: 19841066]

Yadav VK, Ryu JH, Suda N, Tanaka KF, Gingrich JA, Schutz G, Glorieux FH, Chiang CY, Zajac JD, Insogna KL, Mann JJ, Hen R, Ducy P, Karsenty G. Lrp5 controls bone formation by inhibiting serotonin synthesis in the duodenum. Cell. 2008; 135:825-837. [PubMed: 19041748]

Yan Y, Tang D, Chen M, Huang J, Xie R, Jonason JH, Tan X, Hou W, Reynolds D, Hsu W, Harris SE, Puzas JE, Awad H, O'Keefe RJ, Boyce BF, Chen D. Axin2 controls bone remodeling through the beta-catenin-BMP signaling pathway in adult mice. J Cell Sci. 2009; 122:3566-3578. [PubMed: 19737815]

Zhang X, Schwarz EM, Young DA, Puzas JE, Rosier RN, O'Keefe RJ. Cyclooxygenase-2 regulates mesenchymal cell differentiation into the osteoblast lineage and is critically involved in bone repair. J Clin Invest. 2002; 109:1405-1415. [PubMed: 12045254]

Zhou H, Shang L, Li X, Zhang X, Gao G, Guo C, Chen B, Liu Q, Gong Y, Shao C. Resveratrol augments the canonical Wnt signaling pathway in promoting osteoblastic differentiation of multipotent mesenchymal cells. Exp Cell Res. 2009; 315:2953-2962. [PubMed: 19665018] 

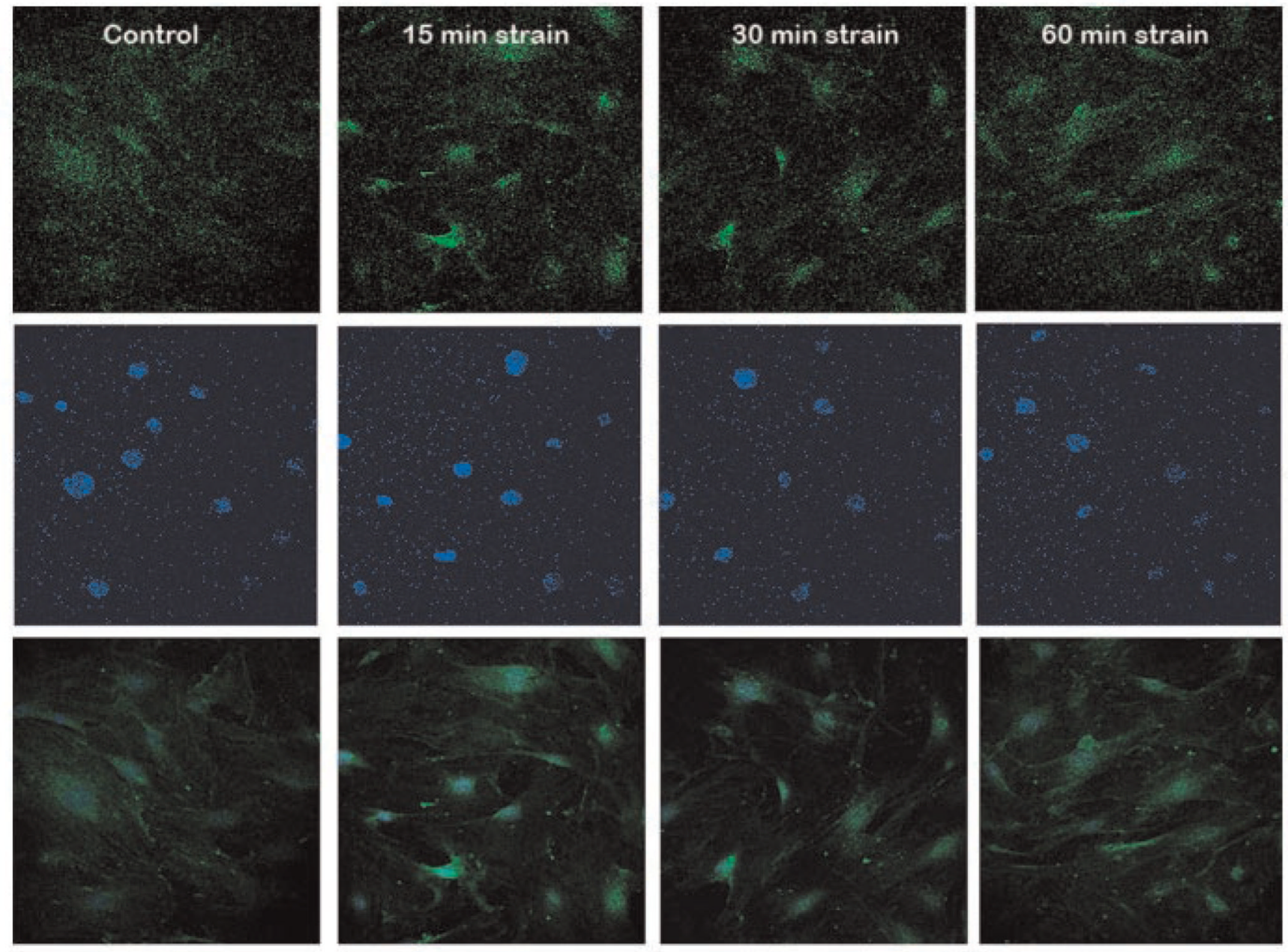

Fig. 1.

Mechanical strain activates $\beta$-catenin translocation. Osteoblast cells were subjected to strain for 15-60 min and immunostained for active $\beta$-catenin (top) and nuclei stained with DAPI (middle). Images of active $\beta$-catenin and DAPI staining were merged (bottom) to show active $\beta$-catenin had translocated to the nucleus. Increased nuclear active $\beta$-catenin was detected 15 min after beginning mechanical strain by confocal microscopy. Adapted from Case et al. [2008]. 


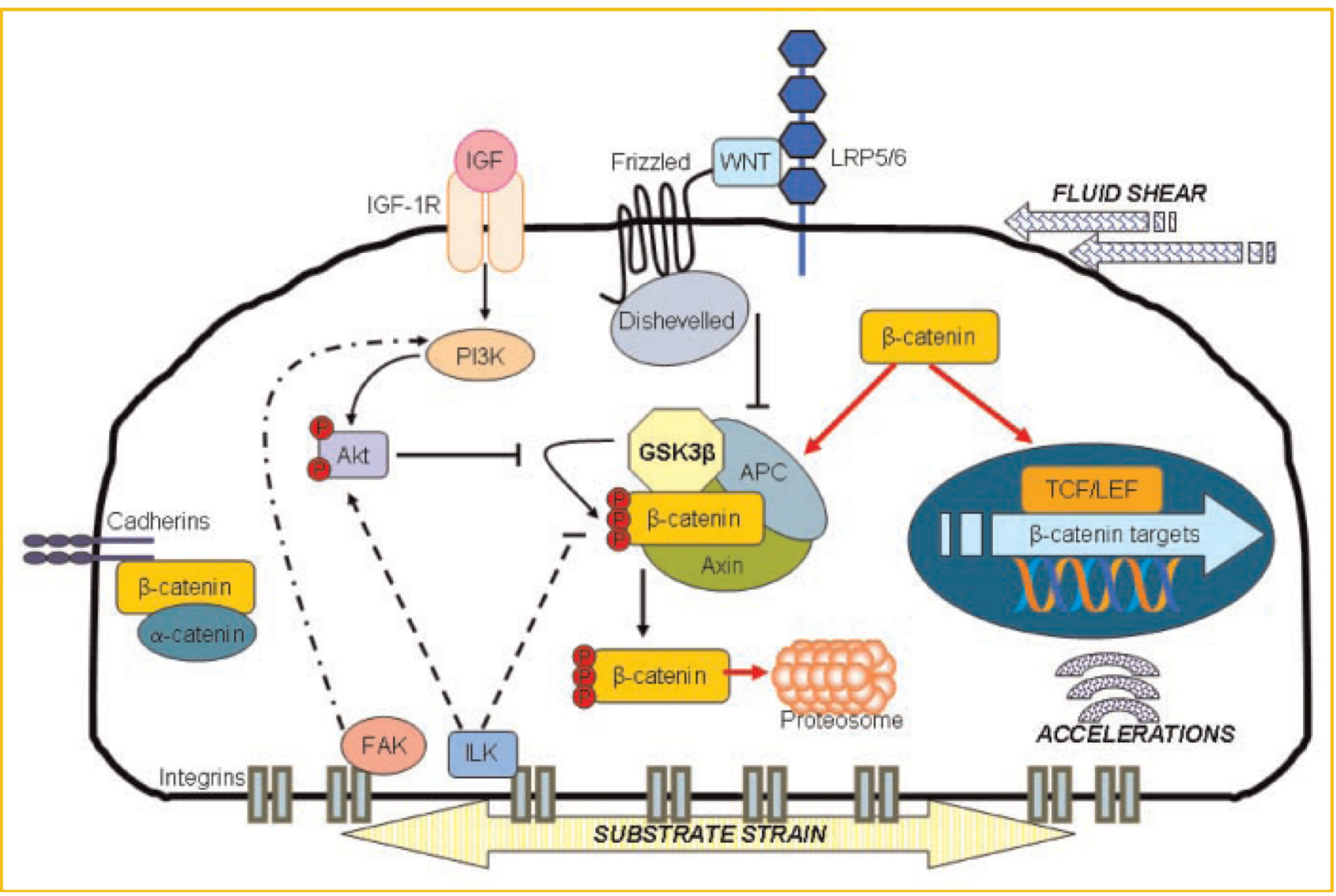

Fig. 2.

$\beta$-catenin activation by mechanical factors is both direct and indirect. $\beta$-catenin signaling is repressed both by sequestration with cadherins and a-catenin at the membrane and by interactions with a multiprotein destruction complex, which targets cytosolic catenin for proteosomal degradation upon phosphorylation by GSK3 $\beta$. Mechanical signals (strain/ deformation, fluid shear, cell acceleration/vibration) in bone cells inhibit GSK3 $\beta$ activity, with Akt being a likely effector by phosphorylation of GSK3 $\beta$ at serine-9. Rapid Akt phosphorylation after mechanical input may occur directly via ILK with involvement of FAK, or more gradually through receptor-dependent actions on PI3K. Prolonged mechanical signaling may also enhance binding of Wnt to its co-receptors, leading to disruption of the destruction complex. Once released from alternative fates such as sequestration, complex binding, or degradation, $\beta$-catenin will translocate to the nucleus, binding to Tcf/Lef transcription factors and triggering cell processes. 


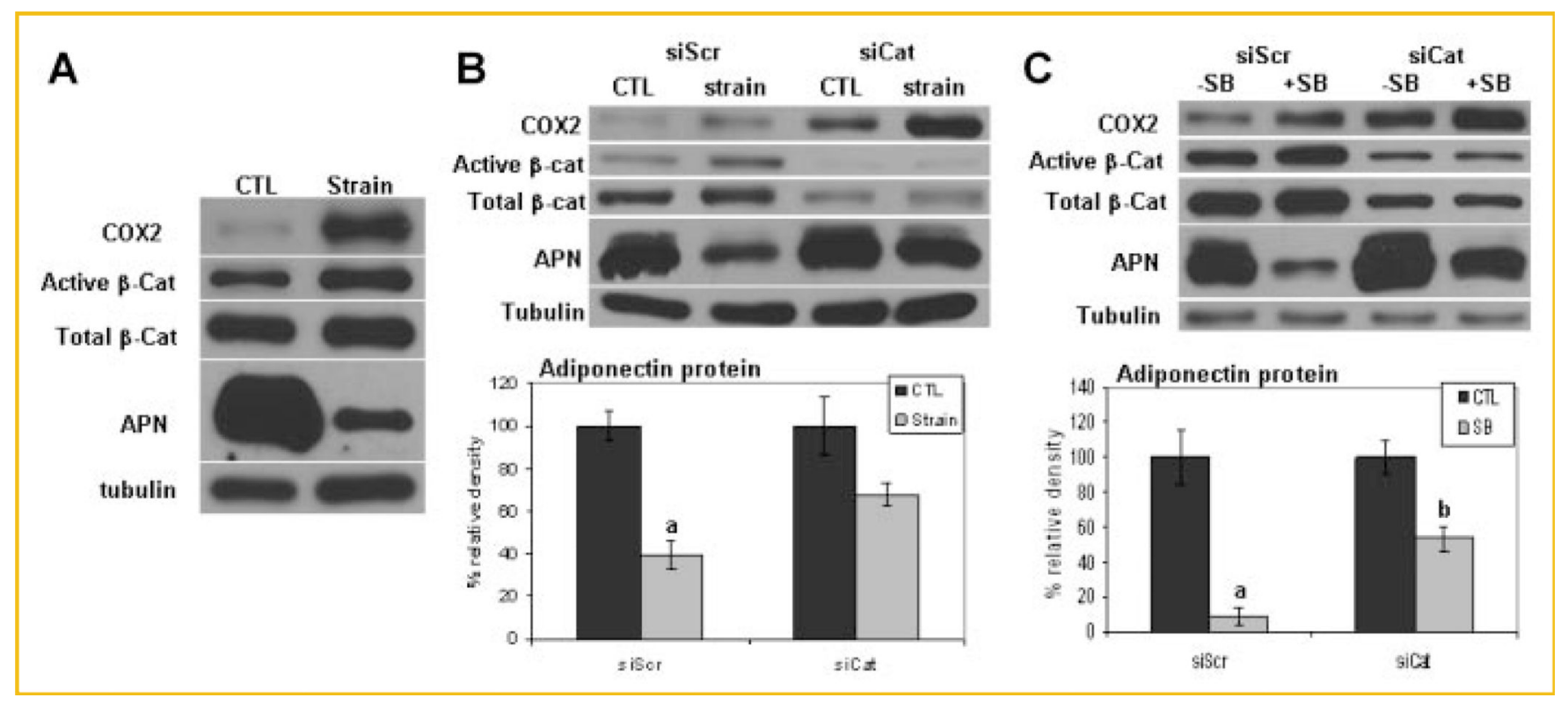

Fig. 3.

$\beta$-catenin is activated by strain and is necessary to transmit both mechanical and pharmacological signals that result in inhibition of adipogenesis. A: MSCs in adipogenic medium were analyzed after exposure to daily strain regimen for 4 days, showing that both active and total $\beta$-catenin are increased by strain. During this time adiponectin, representing adipocyte conversion, is limited by mechanical strain. Note also that COX2 was induced by strain. B: MSCs were treated with siRNA scrambled (siScr) or targeting $\beta$-catenin (siCat) prior to beginning the strain regimen. Strain was unable to prevent adipogenesis when $\beta$ catenin was knocked down (densitometry shown below). $\beta$-catenin was not necessary for strain induction of COX2. C: Similarly, when adipogenesis was prevented by inhibiting GSK3 $\beta$ with the small molecule SB415286 (20 mm), siRNA targeting $\beta$-catenin interfered with this effect. The pharmacologic effect to induce COX2, again, did not require $\beta$-catenin to be effective. Adapted from Sen et al. [2009]. 


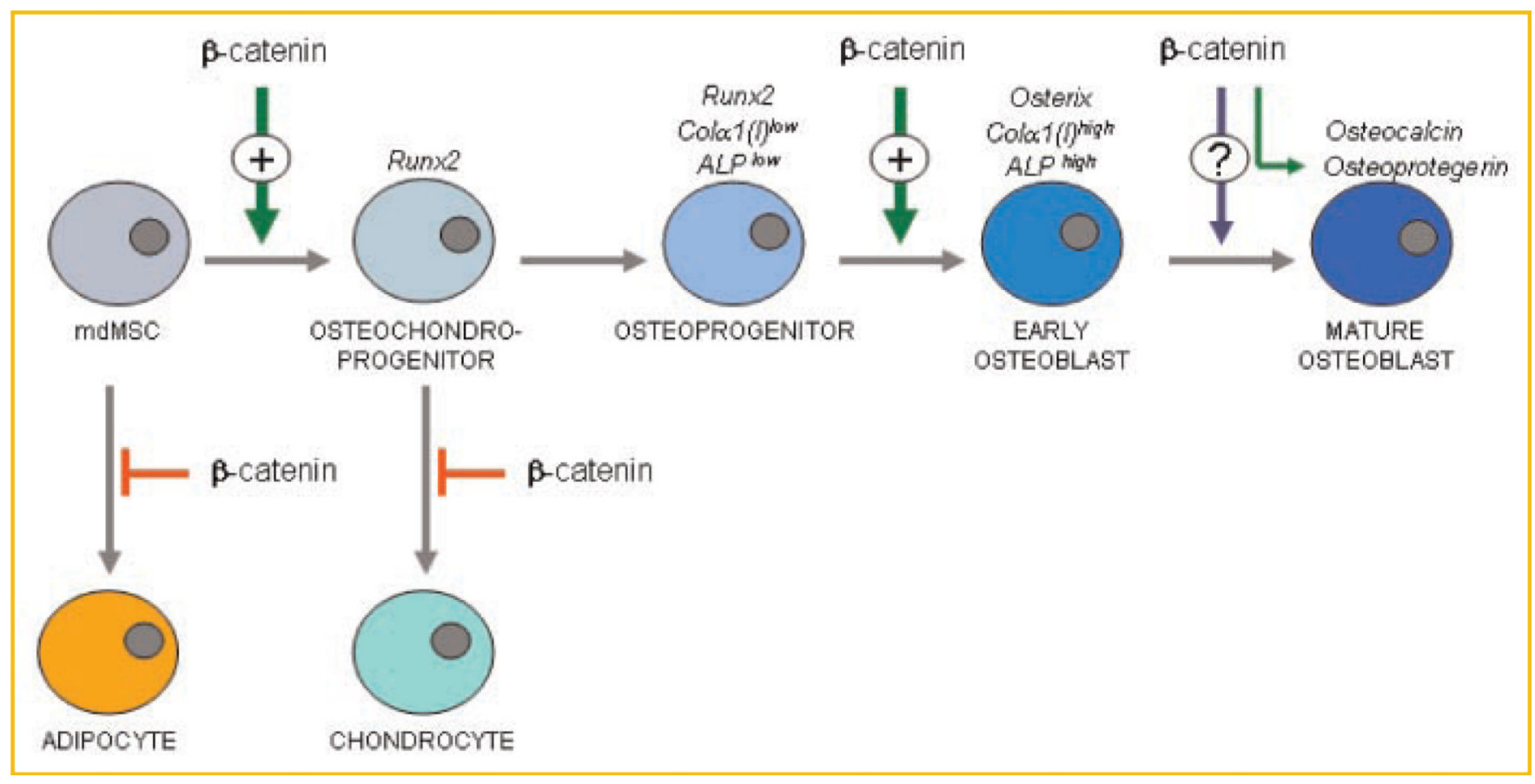

Fig. 4.

$\beta$-catenin restricts MSC distribution to non-osteoprogenitor lineages. Effects of $\beta$-catenin availability and activation prevent loss of precursor cells to the adipogenic phenotype. Once the MSC has become an osteochondroprogenitor, decreases in $\beta$-catenin allow diversion to the chondrocytic lineage. While elevated $\beta$-catenin appears to support the mature osteogenic phenotype, it has yet not been shown to be a singular impetus for this differentiation pathway. 